\title{
Mass Media Exposure and Timing of Antenatal Care Initiation among Women in Uganda
}

Quraish Sserwanja ( $\nabla$ qura661@gmail.com )

GOAL

\section{Linet M. Mutisya}

Swedish Organization for Global Health

Milton W. Musaba

Busitema University

\section{Research Article}

Keywords: Antenatal care, Women, Uganda, Initiation

Posted Date: April 15th, 2021

DOl: https://doi.org/10.21203/rs.3.rs-396658/v1

License: (c) (i) This work is licensed under a Creative Commons Attribution 4.0 International License.

Read Full License 


\section{Abstract}

Background : Early initiation of quality antenatal (ANC) in the first trimester and received quality care are highly emphasized by WHO in the new 2016 guidelines. Mass media have the potential to promote early initiation of ANC because they have been used successfully in several programmes. However, there is a paucity of literature on the impact of media exposure on the timing of ANC initiation in Uganda. Hence our study aimed at exploring associations between the different mass media exposure and timing of antenatal care initiation among women in Uganda.

Methods : A cross sectional study was conducted using the Uganda Demographic and Health Survey (UDHS) 2016 weighted data of 10,152 women of reproductive age (15-49 years). Multistage stratified sampling was used to select study participants. Multivariable logistic regression was used to determine the association between mass media exposure and early initiation of antenatal care. All our analyses were done using SPSS version 25.

Results : Almost a third of the women (2953/10,152, 29.1\%, 95\% Cl: 27.9-29.6) initiated their first ANC contact in the first trimester. In the final multivariable analyses, exposure to television (TV) and radio, belonging to the Northern and Western regions, younger age and less household size each had a significant positive association with earlier ANC initiation while lower education attainment had an inverse association. Women who were exposed to TV (adjusted OR (AOR 1.19, 95\% Cl 1.03 to 1.38) and radio (AOR $1.14,95 \% \mathrm{Cl} 1.01$ to 1.29 ) were $19 \%$ and $14 \%$ more likely to initiate ANC earlier compared to those who were not exposed to TV and radio respectively.

Conclusion : In Uganda, less than a third of women initiated ANC in the first trimester. Young women from a smaller household with access to either a radio or television, and residing in Northern and Western regions were more likely to initiate ANC early enough. In order to promote early initiation of ANC, the government needs to intensify mass media campaigns on local media houses that promote this practice.

\section{Background}

Early initiation of quality antenatal (ANC) in the first trimester and received quality care are highly emphasized by WHO in the new 2016 guidelines [1]. Access to timely and appropriate maternity care has been proven to lead to better maternal and new born outcomes [2]. Unfortunately, there are large disparities in ANC coverage with sub-Saharan Africa and South Asia having the lowest coverage levels [3]. While the benefits of attending ANC are widely known and documented, many women in low and middle income countries are not receiving ANC as per recommended standard of frequency and quality [2]. Antenatal care is an entry point to the utilisation of maternity care services. Early initiation promotes and enables regular monitoring of the pregnant women's health and screen for pregnancy-related complications [4]. Antenatal care if well utilised ensures positive maternal health outcomes such as reductions in stillbirths and complications in pregnancy [3]. Women who utilise ANC are more likely to use 
other essential maternity services such as skilled birth attendance, postpartum care and childhood immunisation $[3,5]$.

Timely care enables health workers to diagnose and manage any pregnancy related complications as soon as possible. Therefore, early initiation of antenatal care has been proposed as one of the key strategies for improving maternal outcomes [6]. It enables health workers to give health education about the importance of skilled birth attendance and danger signs of pregnancy complications, to conduct health tests and medical examinations and give folic acid and iron supplements [6]. Studies have documented that women who initiate ANC early develop confidence in the maternity system and are more likely to have skilled birth attendance and also utilise early postnatal care [6]. Over the last two decades, the utilisation of ANC services in Uganda has improve significantly, but the reduction in maternal and perinatal morbidity and mortality has not been commensurate [7]. For instance, $90 \%$ attend the first ANC contact and $60 \%$ attend atleast four contacts [7], but information on the early initiation of the ANC is limited. An understanding of the level of early initiation of ANC and its determinants will inform the design of interventions to reduce the adverse outcomes of pregnancy despite the significant improvement in the utilisation of maternity services. Several factors including exposure to mass media have been shown to promote the utilisation of maternity care services. Specifically, mass media can be used to disseminate maternal healthcare-related and context specific information to large audiences within a short period of time at relatively low costs [8]. Routine exposure to mass media has been documented to encourage positive or discourage negative health-related behaviours [9]. Mass media awareness campaigns invoke cognitive or emotional responses among women and their partners by informing them about the benefits and risks of utilisation and non utilisation of maternal health services [3]. This information can include awareness of dates, times, and places for screening, or free healthcare, that enables women to take practical action toward healthy behavioural changes [4]Television (TV) and radio are the commonest mass media used in creating awareness however, print media, such as newspapers have also been shown to be effective $[3,10]$.

Mass media have the potential to promote early initiation of ANC in this setting because they have been used successfully in several programmes. However, there is a paucity of literature on the impact of media exposure on the timing of ANC initiation in Uganda. Kisuule et al. in 2012 looked at timing of ANC at a national referral hospital and did not look at the association with mass media exposure [11]. Bbaale analysed the 2011 UDHS and only looked at exposure to radio as one of the variables but did not pay attention to exposure to TV and newspapers [12]. Atuhaire et al. examined interrelationships between early antenatal care, health facility delivery and early postnatal care and further showed that timely initiation of ANC is a mediating factor for health facility delivery and early postnatal care [6]. However, in the analysis, less focus was given to exposure to mass media [6]. Mass media was made a composite variable combining exposure to radio, TV and newspapers which does not give the effect of the separate mass medium on timing of ANC initiation. Hence our study aimed at exploring associations between the different mass media exposure and timing of antenatal care initiation among women in Uganda using the most recent national survey data. 


\section{Methods}

\section{Study design}

We used the 2016 Uganda demographic and health survey (UDHS) data, which was a nationally representative survey. The UDHS collected data on women's sociodemographic characteristics, reproductive health and nutrition indicators $[13,14]$. The UDHS data were collected from June to December 2016 [7] implemented by the Uganda Bureau of Statistics (UBOS) with the technical assistance of Inner City Fund (ICF) International through the USAID-supported MEASURE DHS project [7]. These data were obtained at two-stage cluster sampling. Selection of cluster sample was done at the first stage and then selection of households at the second stage. UDHS 2016 included women aged 15 to 49 years who were either permanent residents or slept in the selected household the night before the survey [7]. In this study, we included women aged 15-49 years who had a live birth within five years preceding the survey and had given informed consent. The UDHS interviewed 18,506 women aged 15-49 years of which 10,152 had a live birth within five years preceding the survey [7].

\section{Outcome Variable}

The primary outcome was early initiation of ANC defined as timing of first ANC contact within the first trimester of pregnancy coded as one (1) and initiation after the first trimester coded as zero (0).

\section{Exposures}

Women were asked whether they read a newspaper or magazine, listen to radio or watch TV almost every day, at least once a week, less than once a week or not at all. Responses were available from only at least once a week, less than once a week and not at all. These variables were recoded to dichotomous variables with response options yes 'yes' (for women who responded at least once a week or less than once a week) and 'no' (for women who responded not at all).

\section{Covariates}

We included determinants of timing of ANC initiation basing on available literature and data [2-4]. Eleven variables were considered and of these, two were community level factors that included; place of residence (rural and urban), and region of residence (Central, East, West and North). Three household level factors included; household size (less than six and six), sex of household head (male and female), and above and wealth index that was categorized into quintiles that ranged from the poorest to the richest quintile. Six individual level factors that included; age (15-24, 25-34 and 35-49), parity (less than 4 and above 4), working status (yes and no), marital status (married and not married), education level of the women and the partner (no education, primary, secondary and tertiary) 


\section{Analytic Approach}

We used Complex sample analysis was performed using SPSS version 25.0 statistical software to account for the multi-stage cluster study design. Proportions and frequencies were tabulated for all the independent variables. Bivariable logistic regression was conducted to assess the association of each independent variable with the outcome and we presented crude odds ratio (COR), 95\% confidence interval (Cl) and p-values. Two multivariable logistic regression models were made with the first one having mass media variables and the final one having other sociodemographic independent variables that were found significant at bivariable level ( $p$-value $<0.25)$. The second model determined whether the association between mass media and timing of ANC initiation remains statistically significant while controlling for other sociodemographic factors. Adjusted odds ratios (AOR), 95\% Confidence Intervals (CI) and p-values were calculated with statistical significance level set at $p$-value $<0.05$. All variables in the model were assessed for collinearity, which was considered present if the variables had a variance inflation factor (VIF) greater than 10. To ensure validity of our study findings, sampling weights provided by UDHS were used. In order to account for the unequal probability sampling in different strata [15] and to ensure representativeness of the study results [16], we applied DHS sample weights. Sensitivity analysis was done with exposure to mass media separated into not all, less than once a week and at least once a week.

\section{Results}

\section{Descriptive statistics}

Table 1 shows percentages of the different socio-demographic characteristics of study participants including exposure to each form of mass media (watching TV, listening to the radio, and reading newspapers). Listening to radio is the most common form of mass media at $73.7 \%$ following by watching television at $29 \%$ and lastly reading newspapers at $19.3 \%$. Most women resided in rural areas (76.9\%), were working (79.0\%), married (81.3\%) and had primary level as the highest level of education (60\%). Almost a third of the women (2953/10,152, 29.1\%, 95\% Cl: 27.9-29.6) initiated their first ANC contact in the first trimester. 
Table 1

Background characteristics of Ugandan women aged 15 to 49 years as per the 2016 UDHS

\begin{tabular}{|c|c|c|}
\hline Category & Frequency $(N=10,152)$ & Percent (\%) \\
\hline \multicolumn{3}{|l|}{ Age } \\
\hline 15 to 24 & 3546 & 34.9 \\
\hline 25 to 34 & 4425 & 43.6 \\
\hline 35 to 49 & 2181 & 21.5 \\
\hline \multicolumn{3}{|l|}{ Residence } \\
\hline Urban & 2346 & 23.1 \\
\hline Rural & 7807 & 76.9 \\
\hline \multicolumn{3}{|l|}{ Region } \\
\hline Western & 2559 & 25.2 \\
\hline Eastern & 2727 & 26.9 \\
\hline Central & 2805 & 27.6 \\
\hline Northern & 2061 & 20.3 \\
\hline \multicolumn{3}{|l|}{ Parity } \\
\hline $0-4$ & 6699 & 66.0 \\
\hline 5 and above & 3453 & 34.0 \\
\hline \multicolumn{3}{|c|}{ Household Size } \\
\hline 6 and Above & 5062 & 49.9 \\
\hline Less than 6 & 5090 & 50.1 \\
\hline \multicolumn{3}{|c|}{ Working status } \\
\hline Not working & 2136 & 21.0 \\
\hline Working & 8016 & 79.0 \\
\hline \multicolumn{3}{|c|}{ Marital status } \\
\hline Married & 8256 & 81.3 \\
\hline Not married & 1896 & 18.7 \\
\hline
\end{tabular}

aMissing 2109 


\begin{tabular}{|c|c|c|}
\hline Category & Frequency $(N=10,152)$ & Percent (\%) \\
\hline No Education & 1061 & 10.5 \\
\hline Primary Education & 6091 & 60.0 \\
\hline Secondary Education & 2285 & 22.5 \\
\hline Higher & 715 & 07.0 \\
\hline \multicolumn{3}{|l|}{ Wealth Index } \\
\hline Poorest & 2117 & 20.9 \\
\hline Poorer & 2074 & 20.4 \\
\hline Middle & 1921 & 18.9 \\
\hline Richer & 1862 & 18.3 \\
\hline Richest & 2178 & 21.5 \\
\hline \multicolumn{3}{|l|}{ Exposure to Radio } \\
\hline No & 2668 & 26.3 \\
\hline Yes & 7484 & 73.7 \\
\hline \multicolumn{3}{|c|}{ Exposure to Newspapers } \\
\hline No & 8188 & 80.6 \\
\hline Yes & 1964 & 19.4 \\
\hline \multicolumn{3}{|l|}{ Exposure to TV } \\
\hline No & 7211 & 71.0 \\
\hline Yes & 2941 & 29.0 \\
\hline \multicolumn{3}{|c|}{ Husband's education level ${ }^{\mathrm{a}}$} \\
\hline None & 517 & 5.1 \\
\hline Primary & 4346 & 42.8 \\
\hline Secondary & 2205 & 21.7 \\
\hline Tertiary & 975 & 9.6 \\
\hline \multicolumn{3}{|l|}{ Sex of household head } \\
\hline Female & 2726 & 26.9 \\
\hline Male & 7426 & 73.1 \\
\hline aMissing 2109 & & \\
\hline
\end{tabular}




\begin{tabular}{|lll|}
\hline Category & Frequency $(\mathrm{N}=10,152)$ & Percent $(\%)$ \\
\hline Timing of ANC & & \\
\hline 1-3 months & 2953 & 29.1 \\
\hline Above 3 months & 7199 & 70.9 \\
\hline aMissing 2109 & \\
\hline
\end{tabular}

\section{Bivariable And Multivariable Analysis}

The final adjusted model in Table 2 shows a positive, statistically significant association between listening to radio and watching TV with timely initiation of ANC contacts. Women who listen to radio were $14 \%$ more likely to initiate ANC contacts in the first trimester compared to those who do not listen to radio (aOR 1.14, 95\% Cl: 1.01-1.29). Women who watch TV were 19\% more likely to initiate ANC contacts in the first trimester compared to those who do not watch TV (aOR 1.19, 95\% Cl: 1.03-1.38). Region, age of the women, household size, level of education of the women were also shown to be significantly associated with timely initiation of ANC contacts. Women in Northern and Western Uganda, those belonging in households with less than five members, aged 25-34 years were more likely to initiate ANC contacts in the first trimester compared to those in Eastern Uganda, those in households with five and above members and those aged 35 to 49 years respectively. Women with secondary level of education (aOR $0.75,95 \% \mathrm{Cl}: 0.56-0.99$ ) were $25 \%$ less likely to initiate ANC in the first trimester compared to those with tertiary education. 
Table 2

Associations between mass media exposure and timing of ANC in Uganda

\begin{tabular}{|c|c|c|c|c|}
\hline Characteristics & $\begin{array}{l}\text { Crude model } \\
\text { COR }(95 \% \mathrm{Cl})\end{array}$ & P-value & $\begin{array}{l}\text { Adjusted model I } \\
\text { AOR }(95 \% \mathrm{Cl})\end{array}$ & $\begin{array}{l}\text { Adjusted Model II } \\
\text { AOR }(95 \% \mathrm{Cl})\end{array}$ \\
\hline Exposure to Radio & & 0.040 & & \\
\hline No & 1 & & 1 & 1 \\
\hline Yes & $1.12(1.01-1.25)$ & & $1.09(0.98-1.22)$ & $1.14(1.01-1.29)$ \\
\hline Exposure to Newspapers & & 0.137 & & \\
\hline No & 1 & & 1 & 1 \\
\hline Yes & $1.11(0.97-1.26)$ & & $1.06(0.92-1.22)$ & $1.02(0.86-1.19)$ \\
\hline Exposure to TV & & 0.129 & & \\
\hline No & 1 & & 1 & 1 \\
\hline Yes & $1.09(0.97-1.23)$ & & $1.05(0.93-1.19)$ & $1.19(1.03-1.38)$ \\
\hline Region & & $<0.001$ & & \\
\hline East & 1 & & & 1 \\
\hline North & $1.70(1.44-2.00)$ & & & $1.68(1.37-2.06)$ \\
\hline West & $1.59(1.35-1.86)$ & & & $1.78(1.44-2.19)$ \\
\hline Central & $1.09(0.91-1.30)$ & & & $1.10(0.89-1.37)$ \\
\hline Residence & & 0.716 & & \\
\hline Urban & 1 & & & \\
\hline Rural & $0.97(0.84-1.28)$ & & & \\
\hline Working status & & 0.141 & & \\
\hline Working & 1 & & & 1 \\
\hline Not working & $0.89(0.78-1.04)$ & & & $0.98(0.85-1.14)$ \\
\hline Marital status & & 0.783 & & \\
\hline Not Married & 1 & & & \\
\hline Married & $0.98(0.87-1.11)$ & & & \\
\hline Education Level & & $<0.001$ & & \\
\hline Tertiary & 1 & & & 1 \\
\hline
\end{tabular}




\begin{tabular}{|c|c|c|c|c|}
\hline Characteristics & $\begin{array}{l}\text { Crude model } \\
\text { COR }(95 \% \mathrm{Cl})\end{array}$ & P-value & $\begin{array}{l}\text { Adjusted model I } \\
\text { AOR }(95 \% \mathrm{Cl})\end{array}$ & $\begin{array}{l}\text { Adjusted Model II } \\
\text { AOR }(95 \% \mathrm{Cl})\end{array}$ \\
\hline Secondary Education & $0.64(0.50-0.82)$ & & & $0.75(0.56-0.99)$ \\
\hline Primary Education & $0.66(0.53-0.83)$ & & & $0.80(0.58-1.09)$ \\
\hline No Education & $0.81(0.63-1.05)$ & & & $0.89(0.62-1.27)$ \\
\hline Wealth Index & & 0.960 & & \\
\hline Richest & 1 & & & \\
\hline Richer & $0.98(0.82-1.18)$ & & & \\
\hline Middle & $0.99(0.84-1.17)$ & & & \\
\hline Poorer & $0.95(0.79-1.13)$ & & & \\
\hline Poorest & $0.96(0.81-1.14)$ & & & \\
\hline Age & & $<0.001$ & & \\
\hline $35-49$ & 1 & & & 1 \\
\hline $25-34$ & $1.32(1.16-1.49)$ & & & $1.22(1.03-1.44)$ \\
\hline $15-24$ & $1.19(1.04-1.35)$ & & & $1.13(0.92-1.40)$ \\
\hline Household size & & 0.004 & & \\
\hline Above 5 & 1 & & & 1 \\
\hline Less than 5 & $1.16(1.05-1.29)$ & & & $1.17(1.03-1.33)$ \\
\hline Parity & & $<0.001$ & & \\
\hline Above 4 & 1 & & & 1 \\
\hline Less than 4 & $1.22(1.10-1.36)$ & & & $1.07(0.90-1.27)$ \\
\hline Sex of household head & & 0.783 & & \\
\hline Male & 1 & & & \\
\hline Female & $0.98(0.88-1.11)$ & & & \\
\hline Age at first birth & & 0.169 & & \\
\hline 18 and above & 1 & & & 1 \\
\hline
\end{tabular}

Bold significant at $p$-value less than 0.05 


\begin{tabular}{|lllll|}
\hline Characteristics & $\begin{array}{l}\text { Crude model } \\
\text { COR }(95 \% \mathrm{Cl})\end{array}$ & P-value & $\begin{array}{l}\text { Adjusted model I } \\
\text { AOR (95\% Cl) }\end{array}$ & $\begin{array}{l}\text { Adjusted Model II } \\
\text { AOR (95\% Cl) }\end{array}$ \\
\hline Less than 18 & $0.93(0.84-1.03)$ & 55 & & $1.05(0.94-1.18)$ \\
& 5 & 66 & & \\
& & $3 f$ & & \\
\hline Partner's education & 148 & 444 & 1 \\
\hline Tertiary & 888 & & \\
\hline Primary & 1 & & 0.001 & $0.89(0.72-1.09)$ \\
\hline Secondary & 1309 & & $0.83(0.67-1.02)$ \\
\hline Primary & $0.77(0.63-0.93)$ & & $1.13(0.85-1.51)$ \\
\hline No education & $0.72(0.59-0.86)$ & & \\
\hline Bold significant at p-value less than 0.05 & & & \\
\hline
\end{tabular}

\section{Sensitivity Analysis}

There were no significant differences in the factors that were positively associated with timing of ANC initiation. Unlike in the original analysis, the first adjusted model in supplementary file 1 showed a positive, statistically significant association between listening to radio and watching TV with timely initiation of ANC contacts. The second adjusted model shows that, controlling for sociodemographic factors, odds ratios for listening to radio slightly reduce with women who listen to radio at least once a week being $14 \%$ more likely to initiate ANC contacts in the first trimester compared to those who do not listen to radio (aOR 1.14, 95\% Cl: 1.01-1.30). The odds ratios for watching TV increased with women who watch TV less than once a week being $28 \%$ more likely to initiate ANC contacts in the first trimester compared to those who do not watch TV (aOR 1.28, 95\% Cl: 1.07-1.53). Region, age of the women, household size and partner's level of education were also shown to be significantly associated with timely initiation of ANC contacts.

\section{Discussion}

This current study was targeted at accessing the association between mass media exposure and timing of ANC initiation. It determines the prevalence of women who initiated their first ANC within the world 
health organization recommended time (1-3 months or first trimester). Ante natal care is the first and critical step in reducing stillbirths and the risk of pregnancy related complications [17]. Attending ANC early provides opportunities for maternal education, iron sulphate and folic acid supplementation and birth preparedness [18]. The factors associated with timing of ANC initiation include exposure to radio, exposure to television, region, level of education, age and household size.

In the present study, the prevalence of women who initiated their first ANC contact in the first trimester was $(29.1 \%)$ and were mostly aged between 25 and 34 years. This finding showed an improvement from a similar study conducted in Uganda in the year 2011 whose finding was (17\%) [12]. Even though the rate is still low, this improvement could be explained by the rigorous interventions the government of Uganda has put in place for the past decade to improve maternal health outcomes. Moreover, the finding was higher compared to a study conducted in Kenya $10.9 \%$ [17] and almost similar with one conducted in Ethiopia (20.1\%) which explored DHS data of 2016 [19].

The descriptive characteristics established the popularity of different forms of mass media among women in Uganda. Overall, radio appeared to be the most popular media source compared with television and newspapers/magazines. It should be noted that the most of women in our study setting reside in rural areas $(79.9 \%)$ compared to those in urban areas $(23.1 \%)$. Public health facilities in rural areas which provide free services are usually less, widely apart from each other and under staffed which negatively affect utilization of care by women $[20,21]$. In such rural settings, reaching all mothers by health workers is hard and therefore, only mass media remains a viable option to reaching families and communities to disseminate message on the importance of early initiation of ANC and availability of such service in their own communities [2].

Exposure to newspaper or magazines was not significant in our study. This could partly be attributed to the fact that most women reside in rural areas where access to Newspapers or magazines is hard and not sustainable due to the daily or weekly costs involved. Furthermore, over $70 \%$ of women having primary level of education and below indicates low literacy levels which negatively affect utilisation of newspapers or magazines. However, radio and TV showed a positive association with timely initiation of ANC. Women who were exposed to radio and Television were $14 \%$ and $19 \%$ more likely to initiate ANC within the first trimester respectively. This finding is consistent with studies conducted in Ethiopia [22]. TV and radio can promote healthy behavioral changes by frequently broadcasting programs and public service announcements supported by the government or non-state actors that describe the benefits of timely initiation of ANC and other maternal healthcare services [4]. They also offer health information services sponsored by the government such as announcements of locations and working hours of health facilities with free maternal healthcare services which encourage women and their partners to take practical action towards healthy behavioral changes [4]. Mass media have been documented to have significant associations with maternal healthcare services such as ANC in other studies [2-4].

Changes in the explanatory power of the mass media (radio and TV) in influencing timely initiation of ANC was observed when socio-economic variables were added in the final adjusted model, indicating that 
socio-economic variables have an influence on timely initiation of ANC by affecting how these mass media messages are received and utilized by women. For instance, lower levels of education showed a negative association with timely ANC initiation while younger age, less household size and Northern region showed a positive association. Education levels affect literacy levels and interpretation of messages which could partly explain why women with secondary level of education were less likely to initiate ANC in the first trimester compared to those with post-secondary education. Women with higher levels of education have been shown to have higher autonomy, better maternal health literacy, be more receptive to new health related information and increased awareness of available health resources which empowers them to make positive health care decisions [16]. Furthermore, women with a higher education level are more likely to listen or watch and assimilate health themed discussions on radio and television better and therefore trigger action by initiating ANC within the recommended time [22]. Radio and TV can easily reach illiterate women and inform them about context specific and scientifically sound information regarding maternal healthcare services [4].

Women aged between 25 and 34 years were found to be more likely to initiate ANC within the recommended time compared to the older women. A similar finding was reported in other studies [22]. The younger women are more likely to listen to radio and watch TV for edutainment and also have better education and literacy levels hence better interpretation of the mass media messages to make positive decisions about their health compared to the older women. Younger mothers have been shown to have more knowledge of modern maternal healthcare services than their older counterparts who tend to think that they already have experience with maternal healthcare $[4,23,24]$ which could negatively affect their utilisation of maternal health programmes on mass media.

Women who live with a household size of less than five were $17 \%$ more likely to initiate ANC within recommended time compared to those who lived in household with more than five. Women in larger households are more likely to have more household chores and responsibilities such as taking care of children, cooking, cleaning tend to have less time for their health matters [25] and to listen to mass media programmes. Large household size might lead to higher expenses and less savings which could affect utilisation of ANC services due to the direct and indirect costs involved.

Women from the Northern and Western regions were positively associated with earlier timing of ANC initiation compared to the Eastern region. Similarly, Rutaremwa et al. using the 2011 UDHS data and Kampala as the reference showed that even if the other four regions were less likely to utilize maternal health services compared to Kampala, Northern region had the highest likelihood of utilizing the desirable maternal health services package compared to other regions [26]. Following the civil war, the Northern region had many interventions and humanitarian aid mainly targeting maternal health services improvement [27]. The other possible explanation could be that many people were residing in internally displaced peoples' camps and these usually have health facilities provided freely near the camps [27]. However, with the civil war and the post-civil war period, mass media such as radio were the commonest source of information hence increased likelihood of high frequency of listening to mass media. 
Western Uganda is among regions with the highest GDP per capita and infrastructure development [28]. As a result of this, women in the Western region might have better access to mass media and healthcare services compared to their counterparts in Eastern Uganda. Besides being one of the poorest region in Uganda, Tetui et al. analyzed health system factors in the Eastern region and showed a staff gap of over $40 \%$ with inadequate medical supplies and inadequate ANC package delivered to women [29]. These factors could partly contribute to poor seeking behaviour in Eastern Uganda contributing to delayed ANC initiation. Uganda has experienced a high rate of economic development and urbanization which is concentrated mainly in the Central region which also happens to be the central business district and location of the capital city $[28,30,31]$. The central region was not significantly associated with timing of ANC initiation even though it houses the country's capital, it's the most developed with good social amenities and health infrastructure but also has a high number of urban poor [32].

\section{Strengths And Limitations}

A strength of this study is that it's the first study to assess the association between mass media exposure and timing of ANC among women. The study utilized Uganda Demographic health survey which is a nationally representative with a high response for women of $97 \%$. Therefore, the findings are generalizable to all women in Uganda. The study was however a cross-sectional survey that restricts the interpretation of causality. UDHS did not collect information on exposure to social media sites such as Facebook that can also impact timing of ANC initiation. Lastly, the dataset did not include information about the content of mother's mass media exposure.

\section{Conclusion}

Late initiation of ANC precludes sufficient time to access the sufficient number of ANC contacts thus missing opportunities for early intervention. Major implications emanating from this study include the need to put targeted interventions to improve utilisation of maternal services that are specific to regional needs, taking advantage of mass media (radio and television) to reach more families and communities. These findings suggest that utilizing mass media to disseminate ANC messages may be an effective approach to improve timely initiation of ANC in Uganda. Our study highlights that radio penetration is broader than other forms of media and has the potential to create mass awareness. These findings can inform maternal health related awareness campaigns in the country to allocate resources to appropriate radio and television media sources to encourage healthy behaviours. The different maternal healthcare stakeholders can implement mass media campaigns to publicize maternal health messages and motivate pregnant women to receive timely maternal healthcare services. There is need to target older women with level of education below tertiary, residing in the Eastern region and from larger households. The government and other organizations can adopt a counselling intervention of early ANC initiation that involve training community health volunteers to provide ANC information to women within their own communities. This has been shown to improve on-time initiation of ANC. For stronger effect, $\mathrm{CHW}$ 
outreach programs can contribute to identifying and getting women into hospital in remote and inaccessible areas focusing in the Eastern region.

\section{Abbreviations}

AOR Adjusted Odds Ratio

Cl Confidence Interval

COR Crude Odds Ratio

DHS Demographic Health Survey

UDHS Uganda Demographic Health Survey

OR Odds Ratio

SD Standard Deviation

WHO World Health Organization

SPSS Statistical Package for Social Science

USAID United States Agency for International Development.

ANC Antenatal care

TV Television

\section{Declarations}

\section{Ethics approval and consent to participate}

High international ethical standards are ensured for MEASURE DHS surveys as ethical approval from the country is obtained from a national ethical review board and local authorities before implementation. Prior to data collection, MEASURE DHS ensures that well-informed verbal consent is sought from the respondents. Internationally, the survey protocol was reviewed and approved by the ICF Institutional Review Board. This data set was obtained from the MEASURE DHS website [33] after getting their permission and no formal ethical clearance was obtained since we conducted secondary analysis of publicly available data.

\section{Consent for publication}

Not applicable. 


\section{Competing interests}

All authors declare that they have no competing interests.

\section{Funding}

No funding was obtained for this study.

\section{Availability of data and materials}

The data set used is openly available upon permission from MEASURE DHS website (URL: https://www.dhsprogram.com/data/available-datasets.cfm).

\section{Authors' contributions}

QS Conceived the idea, drafted the manuscript, performed analysis and interpreted the results. LMM participated in the design of the study and helped in results interpretation and writing. MWM reviewed the first draft and drafted the subsequent versions of the manuscript. All authors read and approved the final manuscript.

\section{Acknowledgements}

We thank the MEASURE DHS program for availing us with the data.

\section{References}

1. Okedo-Alex IN, Akamike IC, Ezeanosike OB, Uneke CJ: Determinants of antenatal care utilisation in sub-Saharan Africa: a systematic review. BMJ open 2019, 9(10):e031890.

2. Acharya D, Khanal V, Singh JK, Adhikari M, Gautam S: Impact of mass media on the utilization of antenatal care services among women of rural community in Nepal. BMC Research Notes 2015, 8(1):345.

3. Dhawan D, Pinnamaneni R, Bekalu M, Viswanath K: Association between different types of mass media and antenatal care visits in India: a cross-sectional study from the National Family Health Survey (2015-2016). BMJ open 2020, 10(12):e042839.

4. Fatema K, Lariscy JT: Mass media exposure and maternal healthcare utilization in South Asia. SSM Population Health 2020, 11:100614.

5. Dixit P, Dwivedi LK, Ram F: Strategies to Improve Child Immunization via Antenatal Care Visits in India: A Propensity Score Matching Analysis. PLoS One 2013, 8(6):e66175. 
6. Atuhaire R, Atuhaire LK, Wamala R, Nansubuga E: Interrelationships between early antenatal care, health facility delivery and early postnatal care among women in Uganda: a structural equation analysis. Global Health Action 2020, 13(1):1830463.

7. Uganda Bureau of Statistics - UBOS, ICF: Uganda Demographic and Health Survey 2016. In. Kampala, Uganda: UBOS and ICF; 2018.

8. Sarrassat S, Meda N, Ouedraogo M, Some H, Bambara R, Head R, Murray J, Remes P, Cousens S: Behavior Change After 20 Months of a Radio Campaign Addressing Key Lifesaving Family Behaviors for Child Survival: Midline Results From a Cluster Randomized Trial in Rural Burkina Faso. Glob Health Sci Pract 2015, 3(4):557-576.

9. Hornik RC, Yanovitzky I: Using Theory to Design Evaluations of Communication Campaigns: The Case of the National Youth Anti-Drug Media Campaign. Communication theory: CT : a journal of the International Communication Association 2003, 13(2):204-224.

10. Wakefield MA, Loken B, Hornik RC: Use of mass media campaigns to change health behaviour. Lancet (London, England) 2010, 376(9748):1261-1271.

11. Kisuule I, Kaye DK, Najjuka F, Ssematimba SK, Arinda A, Nakitende G, Otim L: Timing and reasons for coming late for the first antenatal care visit by pregnant women at Mulago hospital, Kampala Uganda. BMC pregnancy and childbirth 2013, 13(1):121.

12. Bbaale $\mathrm{E}$ : Factors influencing timing and frequency of antenatal care in Uganda. The Australasian medical journal 2011, 4(8):431-438.

13. Sserwanja Q, Mukunya D, Habumugisha T, Mutisya LM, Tuke R, Olal E: Factors associated with undernutrition among 20 to 49 year old women in Uganda: a secondary analysis of the Uganda demographic health survey 2016. BMC Public Health 2020, 20(1):1644.

14. Sserwanja Q, Musaba MW, Mukunya D: Prevalence and factors associated with modern contraceptives utilization among female adolescents in Uganda. BMC Women's Health 2021, 21(1):61.

15. Abrha S, Shiferaw S, Ahmed KY: Overweight and obesity and its socio-demographic correlates among urban Ethiopian women: evidence from the 2011 EDHS. BMC Public Health 2016, 16:636.

16. Dankwah E, Zeng W, Feng C, Kirychuk S, Farag M: The social determinants of health facility delivery in Ghana. Reproductive Health 2019, 16(1):101.

17. Ochako R, Fotso J-C, Ikamari L, Khasakhala A: Utilization of maternal health services among young women in Kenya: Insights from the Kenya Demographic and Health Survey, 2003. BMC pregnancy and childbirth 2011, 11(1):1.

18. Atusiimire LB, Waiswa P, Atuyambe L, Nankabirwa V, Okuga M: Determinants of facility baseddeliveries among urban slum dwellers of Kampala, Uganda. PLoS One 2019, 14(4):e0214995.

19. Woldeamanuel B, Belachew T. Risk Factors Associated With Frequency of Antenatal Visits, Number of Items of Antenatal Care Contents Received and Timing of First Antenatal Care Visits in Ethiopia: Multilevel Mixed-Effects Analysis [Internet]. In Review; 2020 Dec [cited 2021 Mar 6]. Available from: https://www.researchsquare.com/article/rs-110214/v1. 
20. Dowhaniuk N: Exploring country-wide equitable government health care facility access in Uganda. International Journal for Equity in Health 2021, 20(1):38.

21. Konde-Lule J, Gitta SN, Lindfors A, Okuonzi S, Onama VO, Forsberg BC: Private and public health care in rural areas of Uganda. BMC international health and human rights 2010, 10:29-29.

22. Geta MB, Yallew WW: Early Initiation of Antenatal Care and Factors Associated with Early Antenatal Care Initiation at Health Facilities in Southern Ethiopia. Advances in Public Health 2017, 2017:1624245.

23. Ameyaw EK, Tanle A, Kissah-Korsah K, Amo-Adjei J: Women's Health Decision-Making Autonomy and Skilled Birth Attendance in Ghana. International journal of reproductive medicine 2016, 2016:6569514.

24. Chakraborty N, Islam MA, Chowdhury RI, Bari W, Akhter HH: Determinants of the use of maternal health services in rural Bangladesh. Health Promotion International 2003, 18(4):327-337.

25. Abosse Z, Woldie M, Ololo S: Factors influencing antenatal care service utilization in hadiya zone. Ethiopian journal of health sciences 2010, 20(2):75-82.

26. Rutaremwa G, Wandera SO, Jhamba T, Akiror E, Kiconco A: Determinants of maternal health services utilization in Uganda. BMC Health Serv Res 2015, 15:271.

27. Namasivayam A, Arcos González P, Castro Delgado R, Chi PC: The Effect of Armed Conflict on the Utilization of Maternal Health Services in Uganda: A Population-based Study. PLoS currents 2017, 9.

28. Jonathan D. Moyer, Mickey Rafa, Paul Sutton, Xuantong Wang. 2017. "Estimating District GDP in Uganda" Invited Research Paper for USAID. The Frederick S. Pardee Center for International Futures, University of Denver, Denver, CO. https://pardee.du.edu/estimating-district-gdp-uganda.

29. Tetui M, Ekirapa EK, Bua J, Mutebi A, Tweheyo R, Waiswa P: Quality of Antenatal care services in eastern Uganda: implications for interventions. Pan Afr Med J 2012, 13:27.

30. Richmond A, Myers I, Namuli H: Urban Informality and Vulnerability: A Case Study in Kampala, Uganda. Urban Science 2018, 2(1).

31. Mukwaya PI, Sengendo H, Lwasa S: Urban Development Transitions and Their Implications for Poverty Reduction and Policy Planning in Uganda. Urban Forum 2010, 21(3):267-281.

32. Quraish S, Joseph K, Rehemah N. Dimensions of women's empowerment on access to antenatal care in Uganda: a further analysis of the Uganda demographic health survey 2016 [Internet]. In Review; 2021 Feb [cited 2021 Mar 6]. Available from: https://www.researchsquare.com/article/rs279035/v1.

33. DHS. The DHS program. https://www.dhsprogram.com/.

\section{Supplementary Files}

This is a list of supplementary files associated with this preprint. Click to download.

- ANCtimingsupplementary1.docx 